\title{
Atividade de enzimas associadas ao estado de indução em mudas de cacaueiro expostas a dois actinomicetos residentes de filoplano*
}

\author{
Dirceu Macagnan $^{1^{* *}}$; Reginaldo da Silva Romeiro ${ }^{2 * *}$; Maria Cristina Baracat-Pereira ${ }^{3}$; Roberto Lanna-Filho ${ }^{2 * *}$; \\ Gisele Sales Batista ${ }^{2 * *} \&$ Alan Willian Vilela Pomella ${ }^{4}$.
}

CEFET-Rio Verde, Rod. Sul Goiana Km 01-Zona Rural Cx.Postal 66 CEP 75901-970 Rio Verde-GO ²Universidade Federal de Viçosa - UFV Departamento de Fitopatologia ${ }^{3}$ UFV - Departamento de Bioquímica e Biologia Molecular, 36571-000 Viçosa-MG. ${ }^{4}$ Almirante Cacau, Cx.P. 55 CEP 45630-000 Itajuípe-BA.

*Parte da tese de doutorado do primeiro autor. Universidade Federal de Viçosa 2005.

**Bolsistas do CNPq

Data de chegada:07/11/2005. Aceito para publicação em: 15/06/2007

\section{RESUMO}

Macagnan, D.; Romeiro, R.S.; Baracat-Pereira, M.C.; Lanna-Filho, R.; Batista, G.S.; Pomella, A.W.V. Atividade de enzimas associadas ao estado de indução em mudas de cacaueiro expostas a dois actinomicetos residentes de filoplano. Summa Phytopathologica, v.34, n.1, p.34-37, 2008

Dois antagonistas selecionados para o biocontrole da vassourade-bruxa do cacaueiro foram avaliados quanto à capacidade em ativar mecanismos de defesa de plantas contra patógenos. Para tanto, mudas seminais de cacaueiro "comum" foram cultivadas em casa-devegetação por 30 dias e expostas aos antagonistas aplicados a mudas de cacaueiro por atomização, individualmente e em associação. O primeiro par de folhas das mudas dos diferentes tratamentos foi coletado aos dois, quatro, 12 e 24 dias após a exposição aos antagonistas. Foi quantificada a atividade de peroxidases, polifenoloxidases, quitinases e E-1,3-glucanases no material coletado. Observou-se um aumento na atividade de peroxidases e polifenoloxidases nos primeiros dias após a exposição das mudas, especialmente ao isolado Ac26. Não foi observado efeito aditivo ou sinergístico nas mudas expostas aos dois isolados simultaneamente.

Palavras chave: Streptomyces, peroxidases, enzimas líticas, indução de resistência, Theobroma cacao.

\section{ABSTRACT}

Macagnan, D.; Romeiro, R.S.; Baracat-Pereira, M.C.; Lanna-Filho, R.; Batista, G.S.; Pomella, A.W.V. Activity of enzymes associates of induced resistance on cocoa seedlings exposed of two actinomycetes phylloplane residents. Summa Phytopathologica, v.34, n.1, p.3437, 2008

Two antagonists selected for the biocontrol of cocoa witches' broom were investigated for their ability in triggering increases in the activity of enzymes associated to induced resistance. In a greenhouse, thirty days old cocoa seedlings were exposed $t$ antagonists by spraying a propagule suspension of every antagonist or a mixture of them. At two, four 12 and 24 days exposing plants to the antagonists, the first leaf pair of every plant was excised and used for quantifying the activity of peroxidases, poly-phenol-oxidases, chitinases and E-1,3glucanases. There were increases in activity of peroxidases, polyphenol-oxidases, mainly in the case of isolate Ac26. Additive or synergistic effects were not observed as a consequence of exposing plants to both antagonists together.

Additional keywords: Streptomyces, peroxidases, induced resistance, litic enzymes, Theobroma cacao.

A resistência induzida é um fenômeno caracterizado pelo aumento da resistência de plantas contra doenças quando estas são apropriadamente estimuladas. Plantas levadas ao estado de indução quando inoculadas com um patógeno desafiador exibem menor severidade dos sintomas (7). Plantas expostas a um agente indutor de resistência apresentam um aumento na atividade de rotas metabólicas envolvidas na percepção da presença de patógenos em potencial, sinalização bioquímica a pontos distantes do sítio onde o sinal foi originado e, por conseqüência, aumentos nas atividades de enzimas envolvidas na síntese de compostos antimicrobianos, tais como PR proteínas, fitoalexinas e reforço da parede celular (7). Portanto, se a resistência induzida aumenta a atividade de determinadas rotas metabólicas específicas, o estado de indução de plantas expostas a agentes indutores pode ser confirmado por meio da análise da atividade de algumas enzimas-chave envolvidas na resistência de plantas contra patógenos.

Neste sentido algumas enzimas têm sido consideradas indicadoras do estado de indução em plantas. Dentre estas citam-se as enzimas líticas quitinases e E-1,3-glucanases que fazem parte das proteínas de plantas induzidas sob patogênese ou situações correlatas e, de forma genérica, chamadas de PR proteínas (8).

Peroxidases (PO) representam um conjunto de mais de 20 isoenzimas capazes de catalisar a oxidação de vários substratos como substâncias aromáticas, ácido ascórbico e compostos fenólicos, na presença de peróxido de hidrogênio. Os produtos gerados pela ação das POs estão envolvidos na formação da parede celular vegetal, suberização e lignificação (6). A atividade das POs, em plantas infectadas por patógenos, ou em plantas induzidas, estão também ligadas à oxidação de compostos fenólicos, que são tóxicos a patógenos (18). Estas enzimas estão também envolvidas na geração de $\mathrm{H}_{2} \mathrm{O}_{2}$, que por sua vez pode gerar outras espécies ativas de oxigênio, além de apresentar, atividade antimicrobiana (11).

Outra enzima importante para a defesa de plantas, também envolvida em reações de oxidação é a polifenoloxidases (PPOs). Assim 
como as POs, as PPOs oxidam compostos como o ácido ascórbico e fenóis, porém usando oxigênio (18).

Macagnan et al. (10) selecionaram dois promissores antagonistas para o controle biológico da vassoura-de-bruxa (Crinipellis perniciosa) e da podridão-parda (Phytophthora spp.). Estes isolados demonstraram serem produtores de diferentes substâncias envolvidas no biocontrole de doenças de plantas tais como o ácido cianídrico, sideróforos e quitinases além de compostos de baixa massa molecular inibidoreres da germinação de basidiósporos do patógeno (9).

O desenvolvimento desse trabalho teve por objetivo examinar a capacidade dos microrganismos em questão, aditivamente ao antagonismo direto ao patógeno, estimularem mudas de cacaueiro a ativarem seus mecanismos latentes de resistência contra patógenos, por meio da quantificação da atividade de enzimas líticas (quitinases e E-1,3-glucanases) e oxidativas (peroxidases e polifenoloxidases). Adicionalmente, verificou-se a capacidade dos dois antagonistas agirem sinergísticamente ou aditivamente na ativação de mecanismos de resistência quando aplicados em conjunto à mudas de cacaueiro.

\section{MATERIAL E MÉTODOS}

Material vegetal e microrganismos: manutenção, multiplicação e aplicação. Os isolados Ac26 e Ac79 foram selecionados por Macagnan et al. (10). Estes microrganismos tiveram seu rDNA 16S seqüenciado possibilitando posiciona-los como pertencentes a espécie Streptomyces griseus e Streptomyces virginiae respectivamente. Os antagonistas foram preservados em ultrafreezer $\left(-80^{\circ} \mathrm{C}\right)$ emulsificados em glicerol $15 \%$. As culturas foram reativadas e os isolados foram cultivados em meio extrato de solo ágar (12) por 7 dias. Os esporos foram removidos por raspagem e transferidos para meio líquido BD onde foram cultivados por $72 \mathrm{~h}$, sob agitação, em temperatura de $25^{\circ} \mathrm{C}$.

Como material vegetal foram utilizadas mudas seminais de cacaueiro do tipo amelonado comumente cultivado no sul da Bahia e designado "cacau comum" com 30 dias de idade.

A suspensão de cada antagonista foi padronizada para uma $\mathrm{DO}_{540}=$ 0,8 e aplicados nas plantas individualmente e em associação. A combinação dos isolados foi obtida misturando-se as suspensões de cada um dos dois antagonistas na proporção 1:1 (v/v). As suspensões foram aplicadas com o auxílio de um atomizador de Vilbs, acoplado a uma fonte de pressão, até antes do início do ponto de escorrimento, sobre toda a parte aérea das plantas. Como controle, mudas foram tratadas com meio de cultura BD. Cada um dos tratamentos (Ac26, Ac79, Ac26+Ac79 e testemunha) foi aplicado a 36 mudas que após a pulverização foram transferidas para câmara de nevoeiro com temperatura ajustada para $25^{\circ} \mathrm{C}$. Cada tratamento permaneceu em um compartimento separado dos demais por $72 \mathrm{~h}$ quando as mudas foram transferidas para a casa-de-vegetação permanecendo no local até o final do ensaio. De cada tratamento as folhas basais de nove plantas foram coletadas aos dois, quatro, 12 e 24 dias depois da aplicação dos antagonistas. O material coletado foi armazenado em ultrafreezer (-80 ${ }^{\circ} \mathrm{C}$ ) até o momento da execução das análises.

Delineamento para as análises enzimáticas. Por ocasião da execução das análises enzimáticas, as nove mudas dentro de cada tempo de amostragem foram unidas três a três, onde cada grupo de três mudas constitui-se em uma repetição. De cada repetição retirou-se um grama de tecido vegetal (peso de tecido fresco) o qual foi submetido a extração de proteína total. A partir do extrato obtido foram realizadas todas as análises enzimáticas sendo que para cada enzima foram realizadas três reações. Portanto cada enzima em cada um dos quatro tempos amostrados foi ensaiada nove vezes.

Obtenção dos extratos e dosagem de proteína total. As amostras vegetais foram maceradas sob nitrogênio líquido, utilizando almofariz e pistilo. Ao macerado foram acrescentados $3 \mathrm{~mL}$ de tampão fosfato de sódio $50 \mathrm{mM}, \mathrm{pH}$ 6,5, acrescido de polivinilpirrolidona 1 $\%(\mathrm{p} / \mathrm{v})$ e fluoreto de fenilmetilsulfonila (PMSF) $1 \mathrm{mM}$, com posterior centrifugação $\left(30.000 \mathrm{~g}, 25 \mathrm{~min}, 4^{\circ} \mathrm{C}\right)$ e recuperação do sobrenadante (1) os quais tiveram o seu conteúdo total de proteína determinado pelo método de Bradford (2), sendo a albumina bovina sérica como padrão.

Determinação da atividade de peroxidases. Adotou-se o método espectrofotométrico de Hammerschmidt et al. (5), no qual é mensurada a oxidação do guaicol na presença de peróxido de hidrogênio em comprimento de onda de $470 \mathrm{~nm}$. Os resultados foram expressos em unidades de peroxidase. Cada unidade de peroxidase correspondeu à variação de 0,001 no valor da absorbância a $470 \mathrm{~nm}$ por min de reação por $\mathrm{mg}$ proteína total.

Determinação da atividade de polifenoloxidases. Foi determinada em ensaio espectrofotométrico onde se acompanhou o aumento da absorbância à $420 \mathrm{~nm}$, resultante da oxidação do catecol à quinona. Cada unidade de polifenoloxidases correspondeu a variação de 0,001 no valor da absorbância $(420 \mathrm{~nm})$ por min de reação por $\mathrm{mg}$ de proteína (3).

Determinação da atividade de quitinases. Adotou-se o método de Hackman \& Goldberg (4), onde quantificou-se por espectrofotometria o Remazol Violeta Brilhante liberado de "Chitin Azure (SIGMA)" em comprimento de onda de $575 \mathrm{~nm}$. Uma unidade de quitinases correspondeu à variação de 0,001 no valor de absorbância por dia de reação por mg de proteína total.

Determinação da atividade de B-1,3- glucanases. Foi obtida espectrofotometricamente $(595 \mathrm{~nm})$ pela quantificação do Remazol Azul Brilhante R liberado da "laminarina azure" de acordo com o ensaio enzimático sugerido pelo fabricante (16). Uma unidade de B1,3-glucanases correspondeu a variação de 0,001 unidades de absorbância por min por mg de proteína.

\section{RESULTADOS E DISCUSSÃO}

Concentração de proteína solúvel total. Foi observado um aumento na concentração de proteína total nas folhas com o decorrer do tempo para os diferentes tratamentos (Fig.1). As médias da concentração de proteínas nas mudas expostas ao isolado Ac26 foram inferiores às observadas no tratamento controle. Um padrão diferente foi apresentado pelas plantas tratadas com o isolado Ac79 e as plantas tratadas com ambos os isolados. A maior concentração de proteínas foi observada nas folhas dos diferentes tratamentos aos 24 dias após a aplicação dos antagonistas em comparação aos demais tempos amostrados, especialmente naquelas expostas ao isolado Ac79 isoladamente. $\mathrm{O}$ aumento na concentração de proteínas nos tecidos foliares, para tempos maiores de exposição aos antagonistas (Fig. 1), são resultados esperados visto que foram coletadas em todos os tratamentos, nos diferentes tempos as folhas basais das mudas. Assim sendo o acúmulo de solutos em detrimento à quantidade de água é esperado (14). A quantificação de proteínas totais isoladamente não se demonstrou um bom parâmetro para a detecção do estado de indução uma vez que o isolado Ac26 demonstrou os menores acúmulos de proteínas, porém apresentou as maiores atividades enzimáticas.

Atividade de peroxidases. Em linhas gerais a atividade relativa 


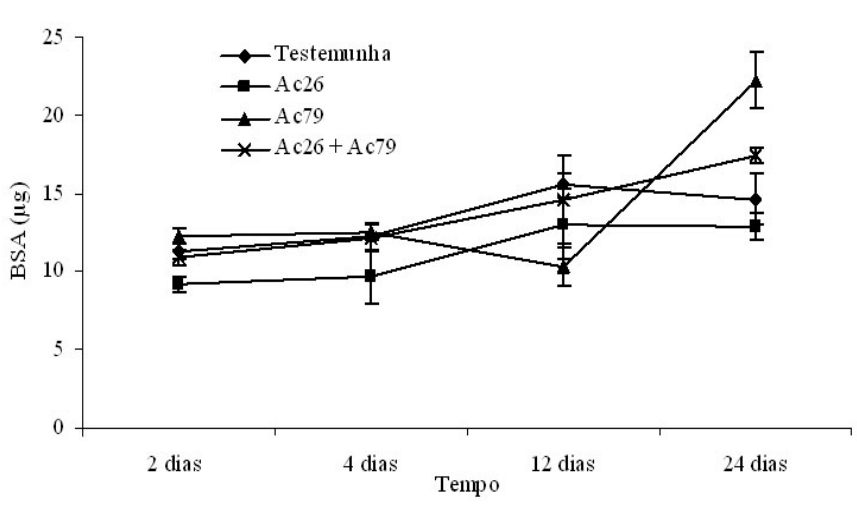

Figura 1. Proteína total presente em folhas de mudas de cacaueiro expostas ou não a dois actinomicetos aplicados isoladamente (Ac26 e Ac79) e em associação (Ac26+Ac79) nos tempos de dois, quatro, 12 e 24 dias após a aplicação dos mesmos. As barras representam o erro padrão da média.

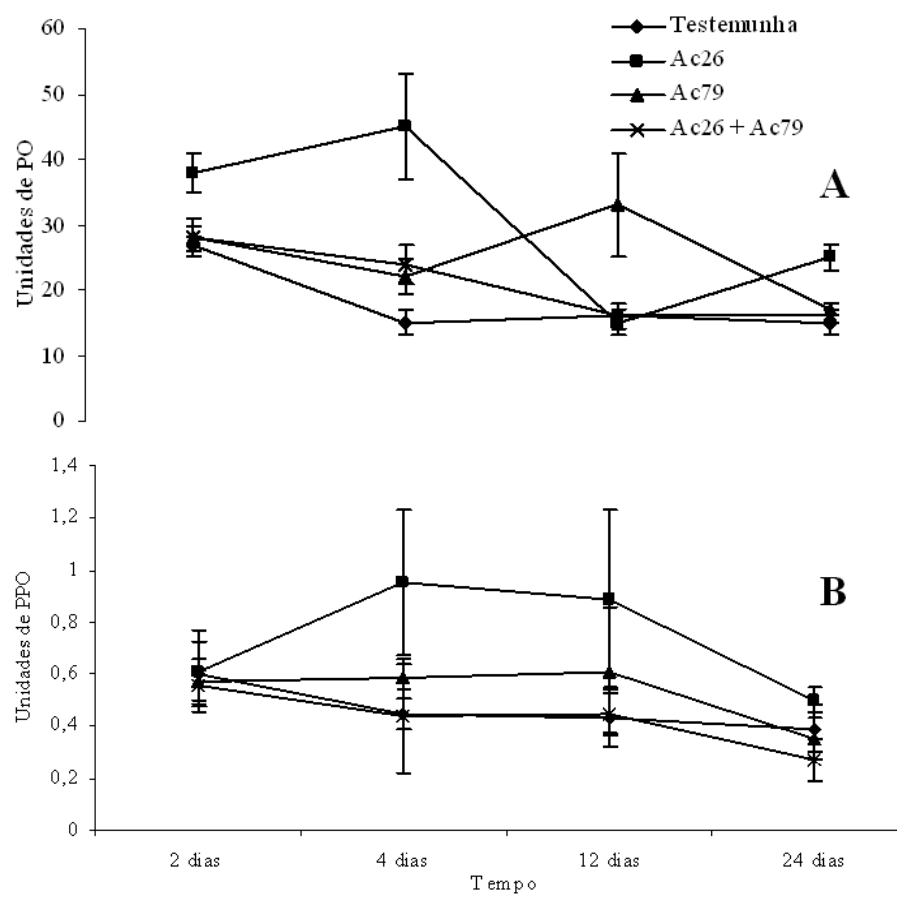

Figura 2. Atividade de peroxidases (A) e Polifenoloxidases (B) em folhas de mudas de cacaueiro expostas ou não a dois actinomicetos aplicados isoladamente (Ac26 e Ac79) e em associação (Ac26+Ac79) nos tempos de dois, quatro, 12 e 24 dias após a aplicação dos mesmos. As barras representam o erro padrão da média.

de peroxidases apresentou decréscimo no decorrer do tempo para todos os tratamentos. Porém, mudas tratadas com os antagonistas aplicados individualmente mantiveram a atividade em patamares mais elevados especialmente nos dois, quatro e 12 dias após o tratamento, especialmente aquelas tratadas com o isolado Ac26 (Fig. 2). Já as mudas tratadas com o isolado Ac79 mostraram esse mesmo padrão, porém somente aos 12 dias após o tratamento (Fig. 2). O decréscimo da atividade relativa das POs no decorrer do tempo pode ser também explicado em função do amadurecimento das folhas (Fig. 2). As POs estão envolvidas na formação da parede celular vegetal, especialmente a síntese de lignina. Logo, durante a fase inicial de desenvolvimento das folhas, há uma contínua deposição de componentes da parede celular. Com a completa expansão foliar, a atividade das POs com funções plásticas diminui (15).

Peroxidases são também componentes da resposta inicial da defesa de plantas contra o ataque de patógenos (19). O envolvimento das peroxidases em respostas de defesa de plantas contra patógenos pode explicar o aumento observado na atividade dessa enzima nas plantas expostas aos antagonistas (Fig. 2). E, a maior atividade observada para os menores períodos de tempo após a exposição das plantas aos antagonistas está de acordo com a afirmação de Tuzun (19) de que peroxidases estão envolvidas nas respostas iniciais de defesa de plantas. Resende et al. (13) já haviam demonstrado que as peroxidases estão envolvidas na indução de resistência em cacaueiros, porém mediada pela aplicação de um indutor abiótico. Siegel (15) sugere a participação das peroxidases em vários mecanismos fisiológicos de defesa. O real envolvimento dessas enzimas em cada um dos possíveis nichos de atuação é difícil de precisar. Porém, a exemplo do observado por Resende et al. (13), pode-se afirmar que, de alguma forma as peroxidases estão envolvidas na indução de resistência em cacaueiro.

Atividade de polifenoloxidases. As mudas expostas ao isolado Ac26 apresentaram os maiores níveis de atividade enzimática especialmente aos quatro, 12 e 24 dias após a exposição. As mudas tratadas com o isolado Ac79 apresentaram atividade inferior à aquelas tratadas com o isolado Ac26 seguido pelas mudas tratadas com ambos os isolados (Fig. 2). As polifenoloxidases apresentaram um comportamento semelhante à POs (Fig 2). As plantas expostas ao isolado Ac26, apresentaram, em termos absolutos, os maiores níveis de atividade dessa enzima aos quatro e 12 dias após a exposição ao antagonista. Porém a variabilidade observada nos dados dificulta a obtenção de conclusões mais precisas.

Enzimas líticas quitinases e \$-1,3-glucanases. Não foi observada atividade expressiva das duas enzimas líticas estudadas em nenhum dos tratamentos ou tempos amostrados (dados não mostrados). Este resultado de certa forma era esperado uma vez que quitinases, sendo PR proteínas, são ativadas pela rota da SAR (systemic acquired resistance). Esta rota é induzida por patógenos ou indutores químicos (17), embora atualmente esta separação entre SAR e ISR (induced systemic resistance) esteja sendo reavaliada. O comportamento das quitinases e $\beta$-1,3-glucanases embora possa ser considerado como esperada uma vez que ambas as enzimas são normalmente induzidas pela rota SAR, se acredita que a maior causa tenham sido imperfeições nas técnicas adotadas.

Não foi observado efeito sinergístico nos tratamentos onde os dois antagonistas foram aplicados em associação. Adicionalmente observou-se, de maneira geral, uma diminuição na atividade das variáveis avaliadas (Fig. 1 e 2). A ausência de aditividade pode estar relacionada com a incompatibilidade entre os isolados que pode ter levado a uma diminuição da persistência dos mesmos no filoplano das mudas. A baixa população individual de cada antagonista pode também ser uma explicação para o fato. A suspensão de cada antagonista teve a densidade ótica ajustada para $\mathrm{A}_{540}=0,8$ e quando aplicados em associação, a concentração individual reduzia-se a $50 \%$ em função da mistura na proporção 1:1. Uma das características da resistência induzida é a ausência do efeito de dose porém, há a necessidade de uma dosagem mínima do agente indutor para desencadear o início da reação (17). Portanto, ao combinar os dois antagonistas estes podem ter sido aplicados em dosagem inferior à necessária para desencadear as respostas de defesa.

Pode-se concluir que os dois antagonistas testados além de produzirem compostos com atividade direta contra o patógeno conforme observado por Macagnan (9), são também capazes de ativar 
mecanismos latentes de resistência de plantas contra patógenos. Este resultado vai de encontro às observações de Loon et al. (7) o qual considera que um microrganismo pode atuar em uma mesma interação como indutor de resistência sistêmica na planta hospedeira e também produzindo substâncias com atividade antagônica ao patógeno causador da doença.

\section{AGRADECIMENTOS}

Os autores agradecem à FINEP pelo financiamento parcial do trabalho (proc. n. 1488/02) e ao CNPq pela concessão das bolsas de estudos.

\section{REFERÊNCIAS BIBLIOGRÁFICAS}

1. Baracat-Pereira, M.C.; Oliveira, M.G.A.; Barros, E.G.; Moreira, M.A.; Santoro, M.M. Biochemical properties of soybean leaf lipoxygenases: Presence of soluble and membrane-bound forms. Plant Physiology and Biochemistry, Paris, v.39, p.91-98, 2001.

2. Bradford, M.M. A rapid and sensitive method for the quantification of microgram quantities of proteins utilizing the principle of protein-dye binding. Analytical Biochemistry, New York, v.72, p.248-254, 1976.

3. Duangmal, K.; Apenten, R.K.O. A comparative study of polyphenoloxidases from taro (Colocasia esculenta) and potato (Solanum tuberosum var. Romano). Food Chemistry, Wageningem v.64, n.3, p.351-359, 1999.

4. Hackman, R.H.; Goldberg, M. New substrates for use with chitinases. Analytical Biochemistry, New York, v.8, p.397-401, 1964.

5. Hammerschmidt, R.; Nuckles, E.M.; Kuc, J. Association of enhanced peroxidase activity with induced systemic resistance of cucumber to Colletotrichum lagenarium. Physiological Plant Pathology, London, v.20, p.73-82, 1982.

6. Kolattukudy, P.E.; Mohan, R.; Bajar, M.A.; Sherf, B.A. Plant peroxidase gene expression and function. Biochemical Society Transactions, London, v.20, n.2, p.333-337, 1992.

7. Loon, L.C.; Bakker, P.A.H.M.; Pieterse, C.M.J. Systemic resistance induced by rhizosphere bacteria. Annual Review of Phyto- pathology, Palo Alto, v.36, p.453-483, 1998.

8. Loon, L.C..; Strien, E.A.. The families of pathogenesis-related proteins, their activities, and comparative analyses of PR-1 type proteins. Physiological and Molecular Plant Pathology, London, v.55, p.85-97, 1999.

9. Macagnan, D. Isolamento e seleção de bactérias endosporogênicas e do tipo actinomicetos visando o biocontrole da vassoura-de-bruxa (Crinipellis perniciosa) e da podridão-parda (Phytophthora spp.) do cacaueiro (Theobroma cacao L) e estudo dos mecanismos de antagonismo ao fungo Crinipellis perniciosa. 2005. 109f. Tese (Doutorado em Fitopatologia) Departamento de Fitopatologia - Universidade Federal de Viçosa, Viçosa, 2005.

10. Macagnan, D.; Romeiro, R.S.; Souza, J.T.; Pomella, A.W.V. Isolation of actinomycetes and endospore-forming bacteria from the cacao pod surface and their activity against the witches' broom and black pod pathogens. Phytoparasitica, Rehovot, v.34, n.2, p.122-132, 2006.

11. Peng, M.; Kuc, J. Peroxidase-generated hydrogen peroxide as a source of antifungal activity in vitro and on tobacco leaf disks. Phytopathology, St. Paul, v.82, p.696-698, 1992.

12. Pramer, D.; Schmidt, E.L. Experimental soil microbiology: Minnesota: Burgess Publishing Company, 1964. 107p.

13. Resende, M.L.V.; Nojosa, G.B.A.; Aguilar, M.A.G.; Silva, L.H. C.P.; Niella, G.R.; Carvalho, G.A.; Giovanini, G.R.; Castro, R.M Perspectivas na indução de resistência em cacaueiro contra Crinipellis perniciosa através do benzotiadiazole (BTH). Fitopatologia Brasileira, Fortaleza, v.25, n.2, p.149 -156, 2000.

14. Salisbury, F.; Ross, C. Plant physiology: 4.ed. Belmont: Brooks Cole, 1991. 682p

15. Siegel, B.Z. Plant peroxidases-an organismic perspective. Plant Growth Regulation, Amsterdam, v.12, n.3, p.303-312, 1993.

16. Sigma. Suitability assay for laminarin azure as a substrate for laminarinase. (www.sigma.aldrich.com. Acessado em março de 2004)

17. Sticher, L.; Mauch Mani, B.; Metraux, J.P. Systemic acquired resistance. Annual Review of Phytopathology, Palo Alto, v.35, p.235-270, 1997.

18. Sutic, D.D.; Sinclair, J.B. Anatomy and physiology of diseased plants: Boston: CRC Press, 1991. 232p.

19. Tuzun, S. The relationship between pathogen-induced systemic resistance (ISR) and multigenic (horizontal) resistance in plants. Europeam Journal of Plant Pathology, Amsterdam, v.107, n.1, p.85-93, 2001 . 